\title{
Novel simultaneous endoscopic ultrasound-guided hepaticoduodenostomy and hepaticogastrostomy for recurrent hepatic hilar obstruction
}

We present the case of a 46-year-old man who had undergone percutaneous sideby-side multi-stent drainage for hepatic hilar obstructive jaundice due to colorectal liver metastases ( $>$ Fig. 1). Six months later, obstructive jaundice was again noted. Contrast-enhanced computed tomography (CT) revealed recurrent hilar obstruction due to tumor ingrowth into the stent.

As there were multiple liver metastases in the right anterior section, we decided to drain the left lobe and posterior section only. We opted for endoscopic ultrasound (EUS)-guided drainage because we anticipated that re-intervention via a trans-papillary approach would be difficult after triple side-by-side stenting ( $>$ Fig. 1).

The EUS scope was inserted into the duodenal bulb where a dilated posterior branch (B6) could be identified ( $\triangleright$ Fig. 2 ). The $\mathrm{B} 6$ branch was punctured using a 19-gauge needle, and a 0.025-inch guidewire was inserted after cholangiographic confirmation. Dilation of the tract was then performed using the ESDilator (Zeon Medical, Tokyo, Japan) and subsequently, an $8 \mathrm{~mm} \times 6 \mathrm{~cm}$ fully covered self-expandable metal stent (SEMSNIR stent; Olympus, Tokyo, Japan) was deployed. As the stent length at the duodenal side was slightly short, we inserted an additional stent of the same size into the existing stent. The EUS-guided hepaticoduodenostomy (HDS) was then complete ( $>$ Fig. 2, $>$ Video $\mathbf{1}$ ).

The EUS scope was then pulled back into the stomach where a hepaticogastrostomy (HGS) was performed to the B2 branch using a method similar to that described above ( $\mathbf{F i g} \cdot \mathbf{3})$. $>$ Fig. 4 shows

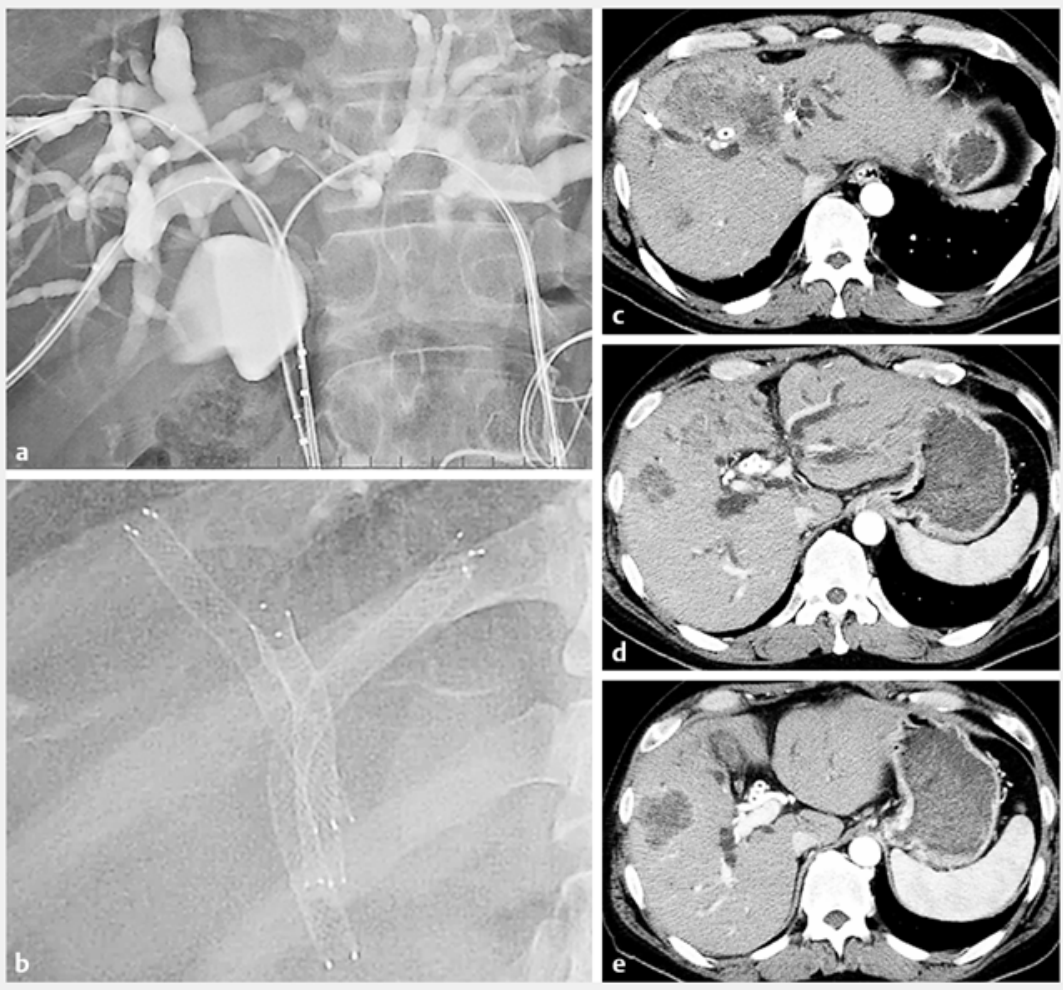

- Fig. 1 Drainage for hepatic hilar obstruction. a,b Percutaneous side-by-side multi-stent drainage was performed. $\mathbf{c}$ The volume of the anterior liver segment was small because of liver metastases. $\mathbf{d}$ The left bile duct was dilated. e The posterior bile duct was also dilated.

the final fluoroscopic and CT images after simultaneous EUS-HDS and -HGS. There were no adverse events. Clinically, the total bilirubin level improved from $7.4 \mathrm{mg} / \mathrm{dL}$ to $0.9 \mathrm{mg} / \mathrm{dL} 14$ days after the procedure. Chemotherapy was then restarted.

There are a few case reports of EUS-HDS in the literature [1-4], but the current case is the first report of simultaneous left and right EUS drainage for hepatic hilar obstruction. It can be anticipated as a new drainage method.

Endoscopy_UCTN_Code_TTT_1AS_2AD

Competing interests

None 

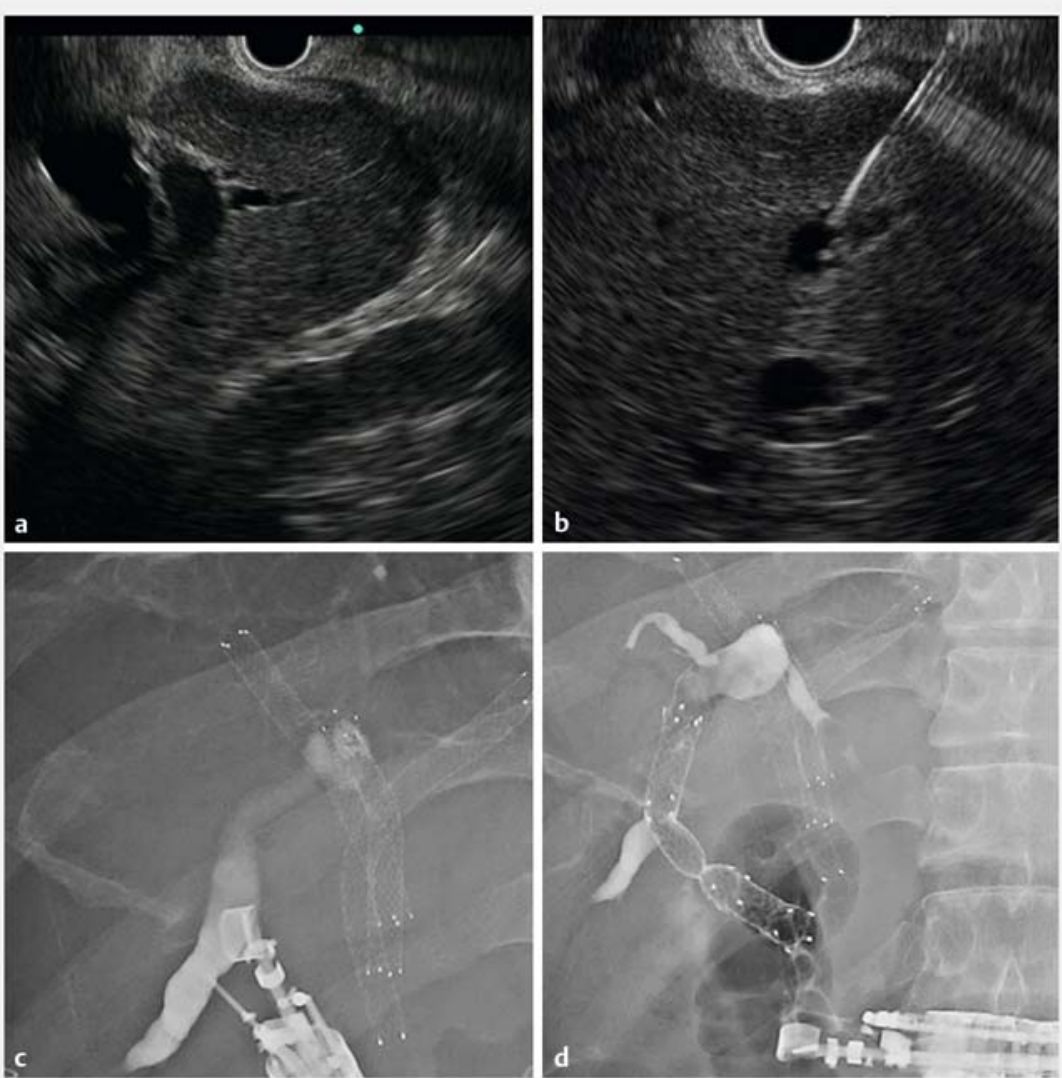

Fig. 2 Endoscopic ultrasound (EUS)-guided hepaticoduodenostomy. a Posterior branch (B6) was clearly visualized by EUS from the duodenal bulb. $\mathbf{b}$ B6 was punctured using a 19-gauge needle. c Cholangiography revealed hilar obstruction. $d$ An $8 \mathrm{~mm} \times 6 \mathrm{~cm}$ fully covered self-expandable metal stent (NIR stent; Olympus, Tokyo, Japan) was deployed.
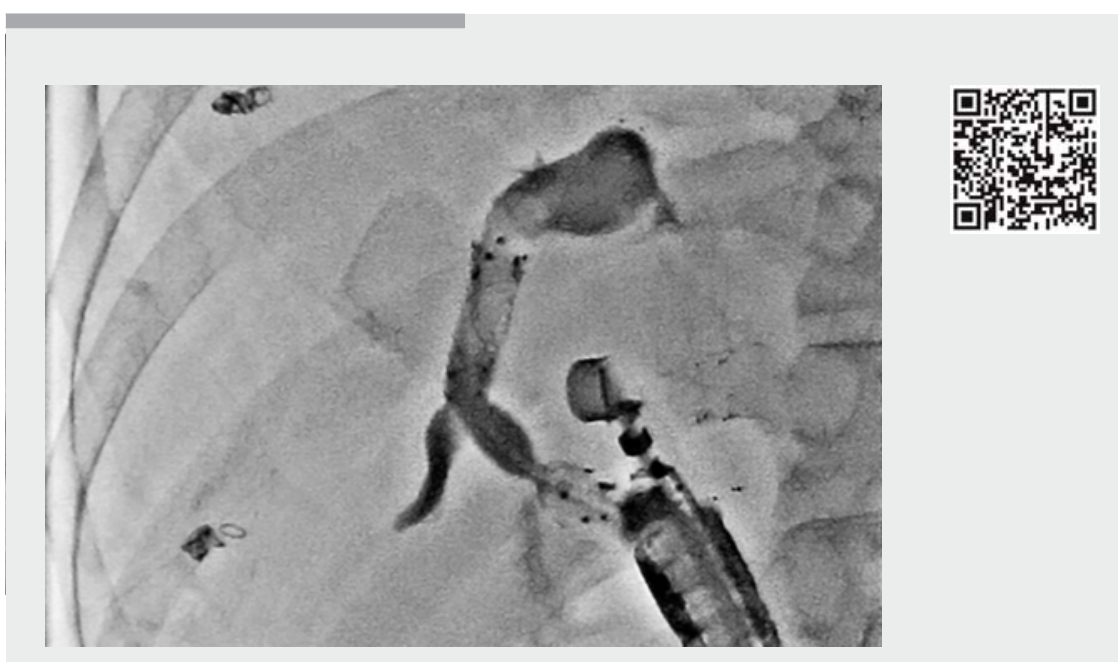

Video 1 Simultaneous endoscopic ultrasound-guided hepaticoduodenostomy and hepaticogastrostomy.
The authors

Susumu Hijioka', Yasunari Sakamoto', Akihiro Ohba ${ }^{1}$, Yuta Maruki ${ }^{1}$, Justin C. Y. Chan $^{2}$, Takuji Okusaka ${ }^{1}$, Yutaka Saito ${ }^{3}$

1 Department of Hepatobiliary and Pancreatic Oncology, National Cancer Center Hospital, Tokyo, Japan

2 Department of Surgery, Princess Margaret Hospital, Hong Kong, China

3 Department of Endoscopy Division, National Cancer Center Hospital, Tokyo, Japan

Corresponding author

\section{Susumu Hijioka, MD}

Department of Hepatobiliary and Pancreatic Oncology, National Cancer Center Hospital, 5-1-1 Tsukiji, Chuo-ku, Tokyo, Japan Fax: +81-52-7635233

shijioka@ncc.go.jp 

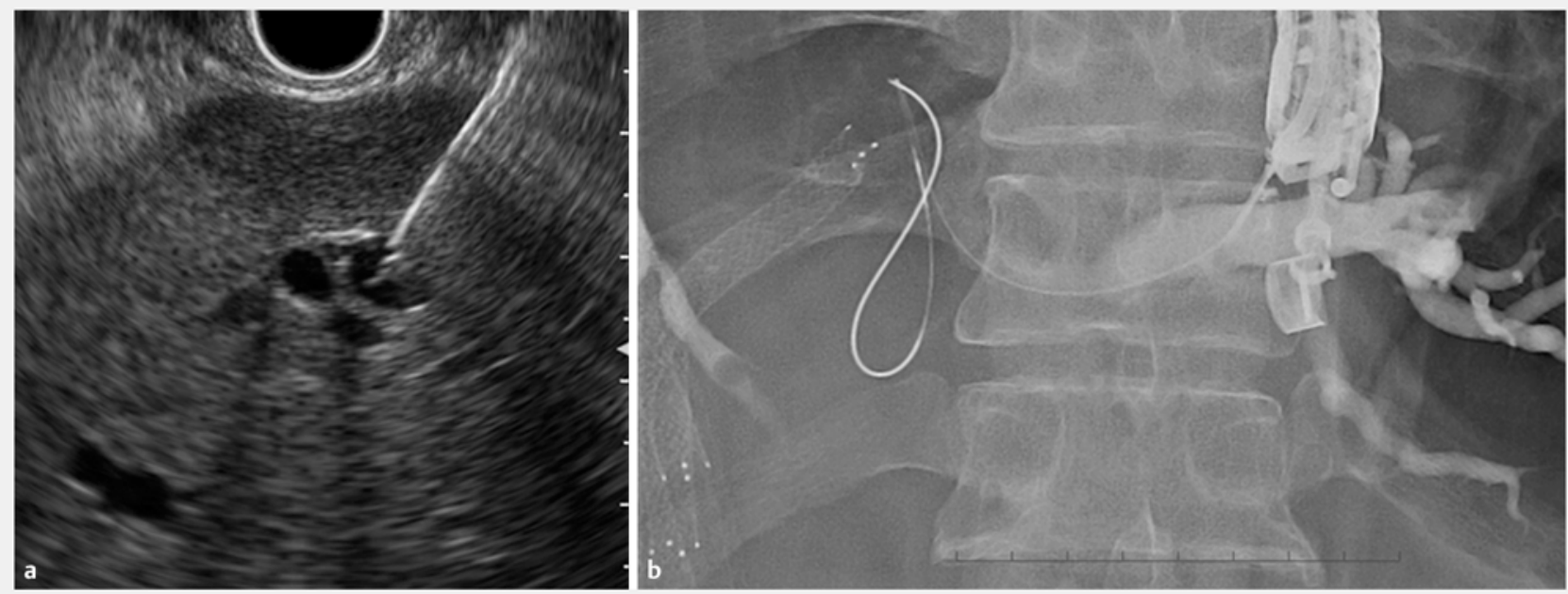

- Fig. 3 Endoscopic ultrasound-guided hepaticogastrostomy. a The dilated left bile duct (B2) was punctured using a 19-gauge needle. b A 0.025 -inch guidewire was inserted after cholangiographic confirmation.
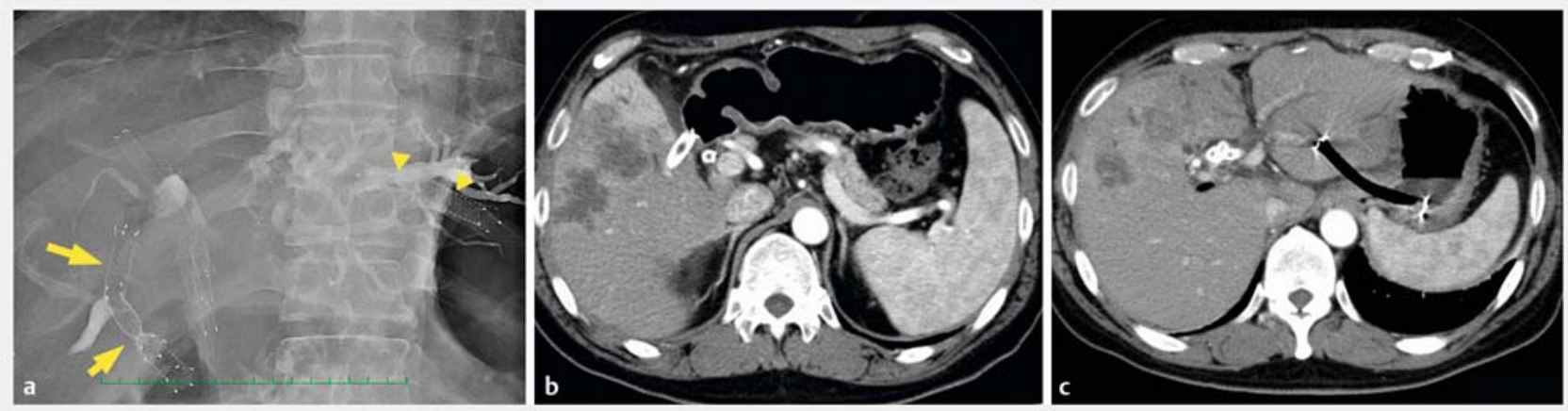

- Fig. 4 Final imaging studies after simultaneous endoscopic ultrasound (EUS)-guided hepaticoduodenostomy (HDS) and hepaticogastrostomy (HCS). a Fluoroscopic image. b Computed tomography (CT) of the EUS-HDS in the posterior segment. c CT of the EUS-HGS in the left lobe.

\section{References}

[1] Minaga K, Takenaka M, Miyata T et al. Achievement of long-term stent patency in endoscopic ultrasonography-guided right bile duct drainage after left hepatic lobectomy (with video). Endosc Ultrasound 2017; 6: $412-413$

[2] Mukai S, Itoi T, Tsuchiya T et al. EUS-guided right hepatic bile duct drainage in complicated hilar stricture. Gastrointest Endosc 2017; 85: 256-257

[3] Ogura T, Sano T, Onda S et al. Endoscopic ultrasound-guided biliary drainage for right hepatic bile duct obstruction: novel technical tips. Endoscopy 2015; 47: $72-75$
[4] Park SJ, Choi JH, Park DH et al. Expanding indication: EUS-guided hepaticoduodenostomy for isolated right intrahepatic duct obstruction (with video). Gastrointest Endosc 2013; 78: 374-380

\section{Bibliography}

DOI https://doi.org/10.1055/a-0665-4256

Published online: 14.8.2018

Endoscopy 2018; 50: E320-E322

(c) Georg Thieme Verlag KG

Stuttgart · New York

ISSN 0013-726X

\section{ENDOSCOPY E-VIDEOS \\ https://eref.thieme.de/e-videos}

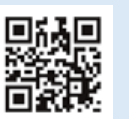

Endoscopy E-Videos is a free access online section, reporting on interesting cases and new techniques in gastroenterological endoscopy. All papers include a high quality video and all contributions are freely accessible online.

This section has its own submission website at https://mc.manuscriptcentral.com/e-videos 